\title{
The Evaluation Anti-HBsAb Titer Among University Students in Shiraz, 2019
}

\author{
Seyed Mohammad Ali Hashemi ${ }^{1,2}$, Fatemeh Hashemzadeh ${ }^{1}$, Helen Bahrampour ${ }^{1}$, Fatemeh Nekooei ${ }^{1}$, \\ Negar Joharinia ${ }^{1}$, Jamal Sarvari ${ }^{1,3^{*}}$ (iD)
}

1. Department of Bacteriology \& Virology, Shiraz University of Medical Sciences, Shiraz, Iran

2. Department of Microbiology, Golestan University of Medical Sciences, Gorgan, Iran

3. Gastroenterohepatology Research Center, Shiraz University of Medical Sciences, Shiraz, Iran

\section{ABSTRACT}

Background: Regarding the availability of an effective vaccine against hepatitis B virus, global vaccination is the best costeffective strategy to prevent HBV infection. However, some people may not respond to the vaccine or the titer of antibody decreases by time. Therefore, the present study aimed to determine the frequency of anti-HBs antibody (anti-HBsAb), among university students in Fars province, southern Iran.

Methods: In this cross-sectional study, 825 medical students were enrolled. Blood samples were taken from the subjects, and the serum separated and stored at $-20 \stackrel{\circ}{ } \mathrm{C}$ until use. Next, HBs Ab titer was measured by ELISA method.

Results: Out of 825 students $54 \%$ was male and $46 \%$ were female. The mean age of the students was $19.5 \pm 1.9$. The titer of anti-HBsAb in 529 (64\%) of subjects was lower than $10 \mathrm{mIU} / \mathrm{mL}$. Significant relationship was observed between age and the titer of anti-HBsAb ( $\mathrm{P}=0.001)$, although no significant relationship was observed between gender $(\mathrm{P}=0.19)$, history of blood transfusion $(P=0.58)$ and the titer of anti-HBsAb.

Conclusion: Finding of this study showed that the titer of anti-HBsAb in more than half of students was lower than $10 \mathrm{mIU} / \mathrm{mL}$ and by time the anti-HBsAb titer decreased, indicating the necessity of measurement of anti-HBsAb titer in medical students.

Keywords: Hepatitis B virus, Antibody titer, Student, Shiraz

Received: 2020/04/12; $\quad$ Accepted: 2020/07/17; Published Online: 2020/08/20

\begin{tabular}{|c|c|}
\hline Corresponding Information: & $\begin{array}{l}\text { Jamal Sarvari, Associate Professor, Department of Bacteriology \& Virology, Shiraz University of Medical Sciences, Shiraz, Iran. } \\
\text { Email: sarvarij@sums.ac.ir }\end{array}$ \\
\hline (c) (1) (9) & $\begin{array}{l}\text { This is an original open-access article distributed under the terms of the Creative Commons Attribution-noncommercial } 4.0 \text { International License which } \\
\text { edistribution of the material just in noncommercial usages with proper citation. }\end{array}$ \\
\hline
\end{tabular}

Use your device to scan and read the article online

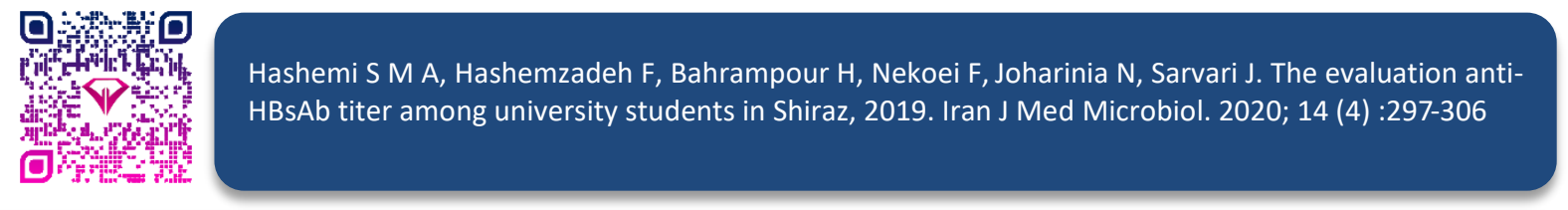

Download citation: $\underline{B i b T e X}$ | RIS | EndNote | Medlars | ProCite | Reference Manager | RefWorks

Send citation to: $\otimes$ Mendeley $\mathbf{z}$ zotero $\hat{H}_{\text {RefWorks }}$

\section{Introduction}

The hepatitis B virus (HBV)-related liver disease is a public health problem worldwide. HBV is classified in the Hepadnavirida family with an incomplete and circular DNA genome (1). The virus is transmitted through parenteral, sexual as well as vertically from mother to fetus (2). Due to the availability of an effective vaccine against the HBV as well as high cost of treatment for the health system, general vaccination is the best way to prevent the transmission of disease as an affordable and efficient strategy. However, some people may not respond to the vaccine or the titer of antibody decreases by time.

Following vaccination, antibodies are produced against a highly immunologic antigen, and the only serological index that appears after vaccination in the serum is anti$\mathrm{HBs} A b$. In exposed subjected to the HBV, in addition to anti HBsAb, the anti- core antibody (anti-HBcAb) is also positive. The antibody titers created below the $10 \mathrm{IU} / \mathrm{L}$ indicate poor immunity, $10-100 \mathrm{IU} / \mathrm{L}$ as moderate 
immunity and the titer higher than $100 \mathrm{IU} / \mathrm{L}$ is considered as good immunity (11). Various studies conducted in different countries show that after a full period of vaccination against the $\mathrm{HBV}, 5-15 \%$ of individuals do not produce enough antibodies. Moreover, the titer of Ab may decrease after vaccination; thereby reduce the rate of immunity against the virus by time (12). Various studies have shown that peoples who produced high level of Abs after vaccination may have longer immunity (13). Moreover, after vaccination, it is essential to investigate the immunological level, especially in people with the possibility of occupational exposure. Therefore, the present study aimed to determine the frequency of anti$\mathrm{HBs} A b$ among university students in Fars province, southern Iran.

\section{Materials and Methods}

\section{Subjects and Sampling}

In this cross-sectional study, 825 students from Shiraz University of Medical Sciences (Shiraz, Iran) were enrolled consecutively. The study performed from September 2019 to January 2020. A questionnaire containing questions about demographic and history of vaccination were filled by participants. Informed written consent was obtained from each participant, and the study was approved by Ethics Committee of Shiraz
University of Medical Sciences (SUMS.MED.REC.1399.47). $5 \mathrm{~mL}$ blood sample were taken from each student, centrifuged and then the separated serum were stored at $-20^{\circ} \mathrm{C}$ until assay.

\section{ELISA for the assay of anti HBs Ab}

The anti-HBs Ab titer was measured using an ELISA commercial kit according to the manufacturer's protocol (DiaPro, Italy). The results were reported as quantitative with $\mathrm{mIU} / \mathrm{mL}$.

\section{Statistical Analysis}

The results of this study were analyzed using SPSS version 26 (SPSS Inc., Chicago, IL., USA) and Chisquared test, and $\mathrm{P}$-value $<0.05$ was considered as a significant level.

\section{Results}

Out of 825 students $54 \%$ was male and $46 \%$ were female. The mean age of the students was $19.5 \pm 1.9$. The titer of anti-HBsAb in 529 (64\%) of subjects was lower than $10 \mathrm{mIU} / \mathrm{mL}$. A significant relationship was observed between age and the titer of anti-HBsAb $(P=0.001)$, although no significant relationship was observed between gender $(P=0.19)$, history of the blood transfusion $(P=0.58)$ and the titer of anti-HBsAb.

Table 1. Demographic and other features of subjects and relative seropositivity to anti-HBsAb among university students in Shiraz

\begin{tabular}{|c|c|c|c|c|}
\hline Variables & $<10 \mathrm{mIU} / \mathrm{ml}$ & $\begin{array}{c}\text { HBsAb titer } \\
\text { HBs Ab Titer }<100 \mathrm{mIU} / \mathrm{ml} \\
10 \mathrm{mIU} / \mathrm{ml}<\end{array}$ & $>100 \mathrm{mIU} / \mathrm{ml}$ & $\mathrm{P}$ value \\
\hline \multicolumn{4}{|l|}{ Sex } & \multirow{3}{*}{$\mathrm{P}=0.19$} \\
\hline Male $(\mathrm{n}=446)$ & $17(3.81 \%)$ & $146(32.73 \%)$ & $283(63.45 \%)$ & \\
\hline Female $(n=379)$ & $24(6.34 \%)$ & $109(28.76 \%)$ & $246(64.9 \%)$ & \\
\hline \multicolumn{4}{|l|}{ Age } & \multirow{3}{*}{$\mathrm{P}=0.001$} \\
\hline$\geq 20(\mathrm{n}=708)$ & $29(4.1 \%)$ & $233(32.9 \%)$ & $446(63 \%)$ & \\
\hline$<20(\mathrm{n}=117)$ & $12(10.26 \%)$ & $22(18.8 \%)$ & $83(70.94 \%)$ & \\
\hline \multicolumn{4}{|l|}{ Majors } & \multirow{13}{*}{-} \\
\hline Medical Student $(\mathrm{n}=233)$ & $11(4.72 \%)$ & $74(31.76 \%)$ & $148(63.52 \%)$ & \\
\hline Nursing (n=138) & $10(7.25 \%)$ & $30(21.74 \%)$ & $98(71.01 \%)$ & \\
\hline Laboratory Science $(\mathrm{n}=84)$ & $6(7.14 \%)$ & $18(21.43 \%)$ & $60(71.43 \%)$ & \\
\hline Anesthesia $(\mathrm{n}=53)$ & $2(3.77 \%)$ & $16(30.2 \%)$ & $35(66.03 \%)$ & \\
\hline Dentistry $(\mathrm{n}=51)$ & $4(7.85 \%)$ & $14(27.45 \%)$ & $33(64.7 \%)$ & \\
\hline Surgical Technologist $(\mathrm{n}=49)$ & $3(6.12 \%)$ & $11(22.45 \%)$ & $35(71.43 \%)$ & \\
\hline $\operatorname{EMT}(n=44)$ & $1(2.3 \%)$ & $18(40.9 \%)$ & $25(56.8 \%)$ & \\
\hline Physical Therapy (n=35) & $0(0.0 \%)$ & $11(31.4 \%)$ & $24(68.6 \%)$ & \\
\hline Radiology Technologist $(\mathrm{n}=32)$ & $3(9.37 \%)$ & $10(31.25 \%)$ & $19(59.3 \%)$ & \\
\hline Midwifery $(\mathrm{n}=22)$ & $0(0.0 \%)$ & $6(27.3 \%)$ & $16(72.7 \%)$ & \\
\hline Occupational Therapy $(n=22)$ & $1(4.55 \%)$ & $7(31.81 \%)$ & $14(63.63 \%)$ & \\
\hline Others major $(n=62)$ & $1(1.61 \%)$ & $23(37 \%)$ & $38(61.3 \%)$ & \\
\hline Blood Transfusion $(n=48)$ & $2(4.17 \%)$ & $16(33.33 \%)$ & $30(62.5 \%)$ & $\mathrm{P}=0.58$ \\
\hline
\end{tabular}

EMT: Emergency medical technician 


\section{Discussion}

Finding of this study showed that the titer of anti-HBsAb in $529(64 \%)$ of subjects was lower than $10 \mathrm{mlU} / \mathrm{mL}$. The significant relationship was observed between age and the titer of anti-HBsAb, although no significant relationship was observed between gender, history of the blood transfusion and the titer of anti-HBsAb.

The understanding of effective and safe vaccination of hepatitis $B$ is one of the most significant developments in medical science in the twentieth century. One of the most important ways to prevent morbidity and mortality related to $\mathrm{HBV}$ is a vaccination for all newly born babies, and the population is at risk. Finding of this study showed that the titer of anti-HBsAb in more than half of students was lower than $10 \mathrm{mIU} / \mathrm{mL}$ and by time the anti-HBsAb titer was decreased, indicating the necessity of measurement of anti-HBsAb titer in medical students. Taiwan, which was an endemic area for chronic HBV infection and liver cancer, was the first place to start the child's general vaccination program in 1986 and recent studies have reported the efficacy of the long-term effect of this vaccination program in reducing liver cell carcinoma (14). The general vaccination program for infants in Iran started in 1993 (15). The routine program of neonatal and pediatric vaccination has significantly changed the epidemiology of HBV and has reduced the cancer of liver cells around the world $(12,16)$. Rad et al. investigated the titer of anti-HBsAb in subjects with the ages of 1 to 18 years old in Ahvaz and found that the anti$\mathrm{HBsAb}$ titer $\geq 10 \mathrm{mIU} / \mathrm{mL}$ among the children with the age one and teenagers 18 years were $\% 90$ and \% 48.9 respectively. They showed that, there was a significant relationship between the reductions of antibody titers with age (13). In a meta-analysis study Rezaei et al. showed that with age increase, the number of respondents in the vaccine was reduced significantly. ( $P$ $=0.001$ ) There was no significant difference between the two groups in terms of gender, vaccines, ethnicity, and living place. Also, the meta-analysis was shown that based on Iranian research and other international research, there is no significant difference between the lacks of response to HBV vaccine (12).

According to studies, although the rate of response to the vaccine varies from country to country, the rate of response to the vaccine in childhood is higher than in adulthood. Several factors have been mentioned in connection with the lack of response to vaccines and reducing the antibody titers in various studies. However, due to the decrease in antibody titers over time, it is necessary to inject a booster dose in individuals who are likely to have an occupational exposure to the virus. The results of our study showed that there was a significant relationship between age and antibody titer and with increasing age, antibody titer was decreased.

Moreover, a series of studies have shown that about $5 \%$ of individuals with a healthy immune system do not respond to vaccines after receiving regular vaccination periods and even after receiving booster doses (11). The factors that might be related to lower rate of responsively to the vaccine include male gender, diabetes, chronic liver disease, genetics background and smoking $(23,24)$. Other factors include vaccine storage, intervals time between injections and inappropriate concentration of injected vaccine $(\mathbf{1 1}, \mathbf{2 4 )}$. Moreover, another factor that is important in the efficacy of vaccines and the production of neutralizing antibodies is the nature of the vaccine, and there are several different strategies that might improve the effectiveness of the vaccine. In the second generation that produced in yeast a part of HBs antigen that plays an essential role in virus attachment is used for the stimulation of neutralizing antibodies (21). The third generation of vaccines that produced in mammalian cells, increases the production of neutralizing antibodies in non-responder individuals (25). It is also reported that using appropriate adjuvants can improve the effect of HBV vaccine and its response in these individuals (26). Fabrizi et al. reported that using a higher dose of Timopentin as adjuvant can lead to an increase in the response rate to HBV vaccination (27).

\section{Conclusion}

In conclusion, the results of this study indicated that by time, the level of immunity against hepatitis B virus is decreased. So it is necessary for high-risk groups including students of medical sciences, that the antiHBsAb titer were examined, and if the titer was lower than $10 \mathrm{mIU} / \mathrm{mL}$, the booster dose was recommended.

\section{Acknowledgment}

The study was financially supported by the office of vice-chancellor for research of Shiraz University of Medical Sciences (Grant No 98-01-01-21063). The study was the subject of the MD dissertation of Fatemeh Hashemzadeh. The authors thank the staff of the Department of Bacteriology and Virology as well as all the students who attended in this research. 


$$
\begin{aligned}
& \text { مجله ميكروبشناسى يزشكى ايران } \\
& \text { سال If _ شماره F _ مرداد و شهريور 99 } \\
& \text { Journal homepage: www.ijmm.ir }
\end{aligned}
$$

\section{ارزيابى تيتر آنتىبادى ضد آنتىزن سطحى ويروس هياتيت B در دانشجويان ورودى سال 19 ا دانشكاه علوم يزشكى شيراز، ايران}

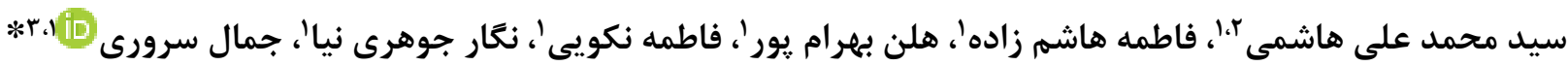

$$
\begin{aligned}
& \text { '. . كروه باكترى و ويروس شناسى، دانشكده يزشكى، دانشخاه علوم يزشكى شيراز، شيراز، ايران }
\end{aligned}
$$

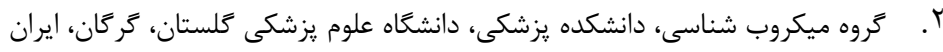

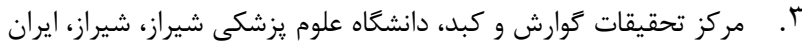

\section{جكيله}

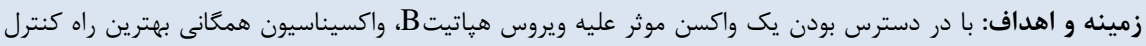

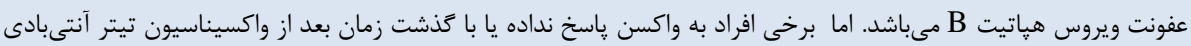

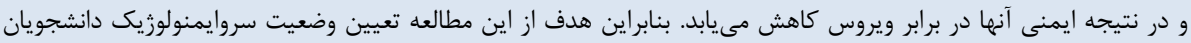

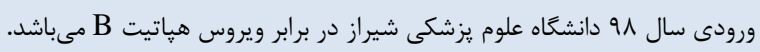

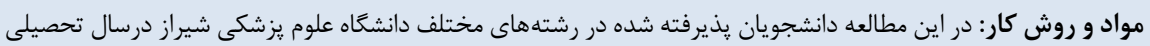

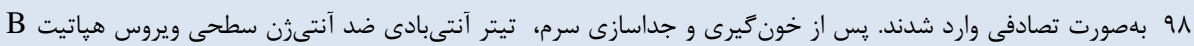

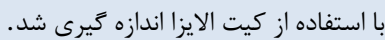

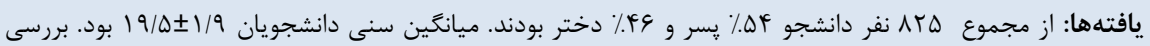

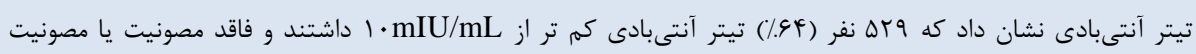

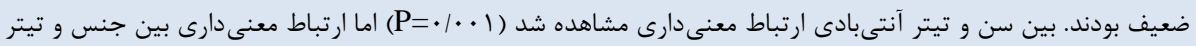

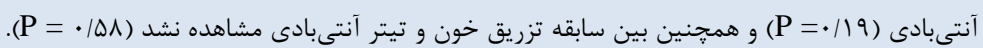

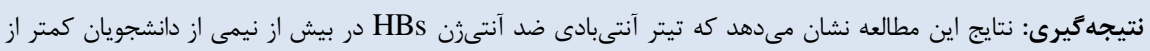
أl mIU/mL

$$
\text { دانشجويان علوم يزشكى نشان مى دهد. }
$$

$$
\text { كليد وازهها: ويروس هياتيت B، تيتر آنتىبادى، دانشجويان، شيراز. }
$$

\section{اطلاعات مقاله - اله}

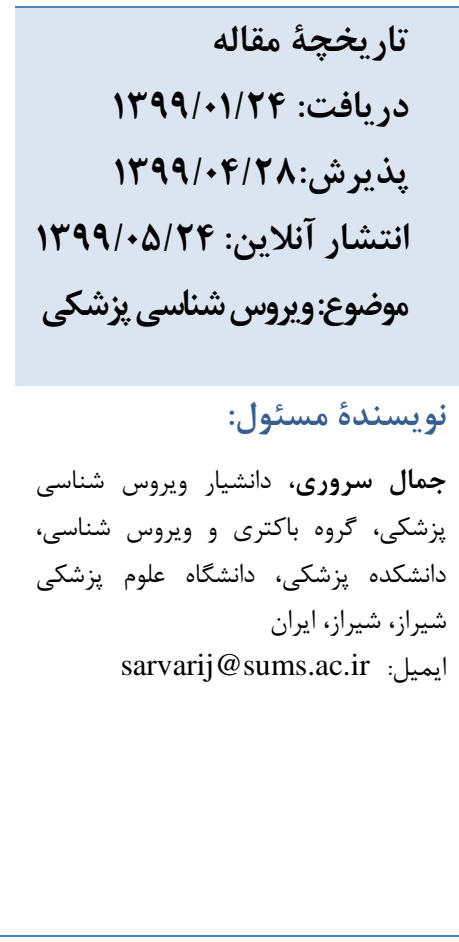

مقدمه - مقه

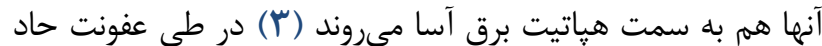
هياتيت B، ماركرهاى ويروسى شامل آنتىخن سطحى ويروس هياتيت

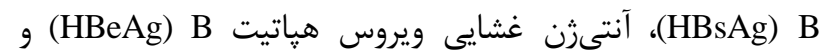

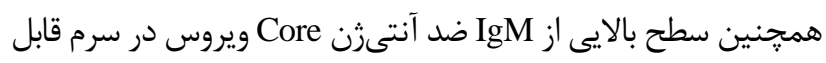

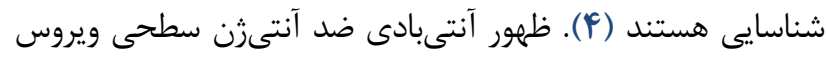
هياتيت B نشان دهندة بهبود عفونت حاد (f) و حضور آنتىثن سطحى ويروس هياتيت B بيش از 8 ماه از زمان تشخيص اول نشان دهندة مزمن شدن عفونت مىباشد (1). با توجه به سن ابتلا به بيمارى،
ويروس هياتيت B در خانواده هيادنا ويريده طبقه بندى شده و

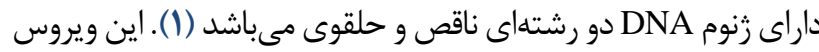
از طريق تماس يوست آسيب ديده و مخاط با خون و مايعات بدن فرد

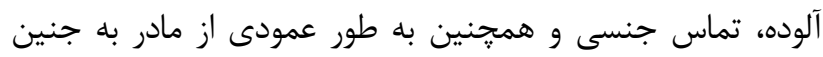

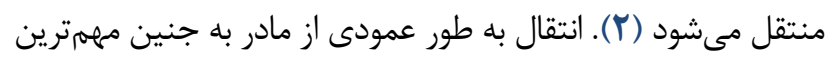
راه انتقال در مناطق اندميك مىباشد (1). عمده عفونتهاى حاد هياتيت B در بزر گسالان بدون علامت مى باشد و تنها حدود • "ادرصد

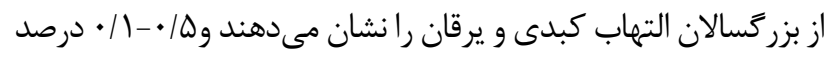


روش يزوهش

\section{نمونه كيرى}

اين مطالعه توصيفى-تحليلى بر روى دانشجويان ورودى سال 19 با دانشكاه علوم يزشكى شيراز (شيراز، ايران) انجام شد. ابتدا رضايت نامه كتبى از دانشجويان دريافت شده و شركت كنندكان

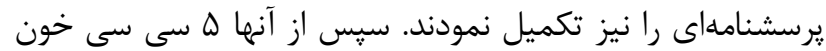
وريدى كرفته شد. يس از لخته شدن و سانتر يفوز، سرم نمونهها جدا

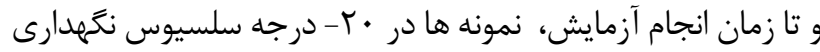

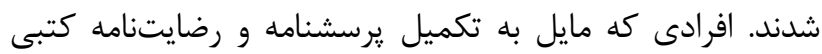
نبودند، از مطالعه حذف شدند.

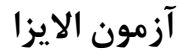

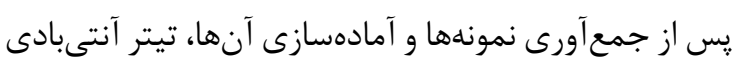
ضد آنتىرن سطحى ويروس هياتيت B با استفاده از كيت تجارى إنى طبق يروتكل كيت اندازمخيرى شد و نتايج به هبه (DiaPro, Italy) صورت كمى و با واحد mIU/mL كزارش شد.

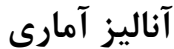

نتايج حاصل از اين مطالعه با استفاده از نرم افزار SPSS ورثن آن

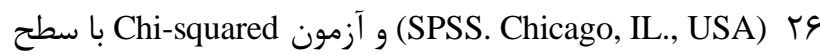
اطمينان 99/Q درصد (P >0.05) آناليز شد.

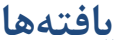

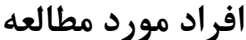

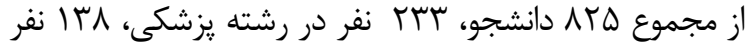

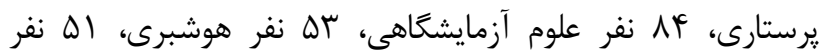

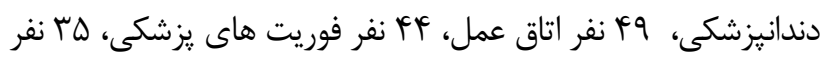

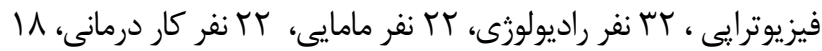

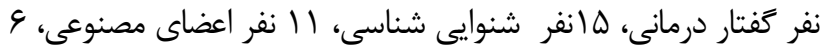

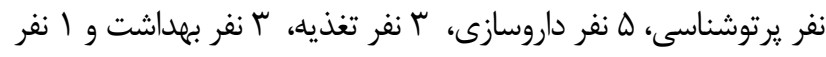

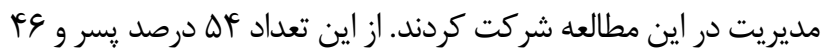
درصد دختر بودند. ميانگين سنى دانشجويان 1/9/4 19 بود. همجنين در اين مطالعه ^^ץ نفر از دانشجويان سابقه تزريق خون داشتند.

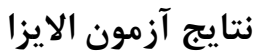

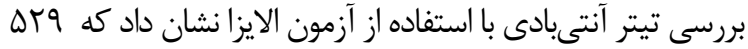

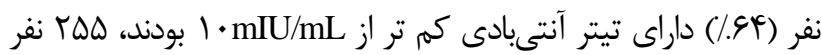

روند بيمارى و مزمن شدن آن، متفاوت است. در بزرگسالان كمترين

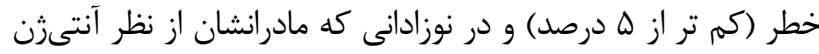
غ مثايى ويروس هياتيت

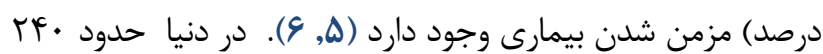
Bيليون و در ايران V9/ادرصد افراد ناقل مزمن ويروس هياتيت هستند (V). ناقل هاى مزمن هياتيت در خطر بالايى براى ييشرفت به سمت سيروز و سرطان سلولهاى كبدى هستند. اين ويروس علت مرى ه/ • تا ا ميليون نفر در سال است (1--(1). با توجه به در دسترس بودن يك واكسن موثر عليه ويروس

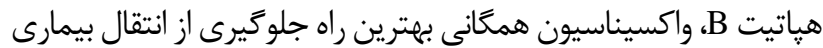

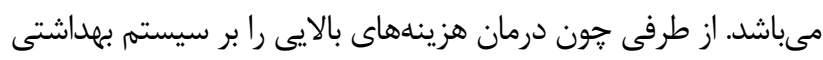
وارد مى كند واكسيناسيون همكانى يك استراترى مقرون به صرفه و كارآمد مىباشد. در ايران برنامه واكسيناسيون عمومى هياتيت B براى

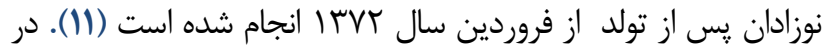
حال حاضر سه نسل از واكسنهاى هياتيت B وجود دارد. به دنبال واكسيناسيون، آنتىبادى عليه آنتىثن بسيار ايمنولوزيك آنتىثن آنائ سطحى ويروس هياتيت B توليد مىشود كه باعث ايمنى افراد در برابر إين ويروس مىشود. در صورتى كه آنتىبادى توليد شده عليه اين آنسائ

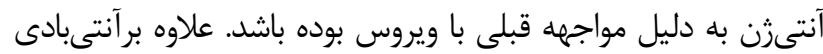

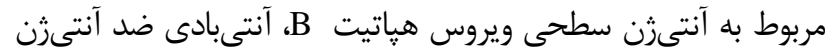

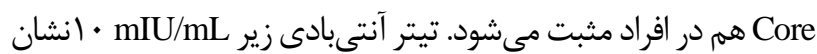
دهندة مصونيت ضعيف، mIU/mL • ا- · · امصونيت متوسط و بالاتر

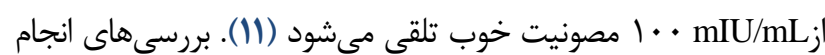
شده در كشورهاى مختلف نشان مىدهد بِ إز يك دوره كامل

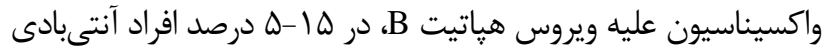

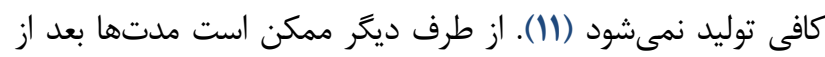

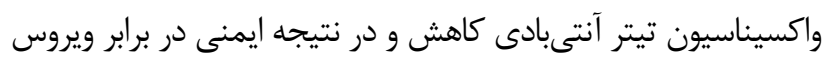

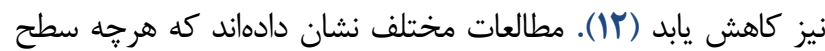
آنتىبادى توليد شده به دنبال واكسيناسيون بيشتر باشد، طول مدت

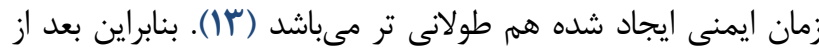
واكسيناسيون بررسى وضعيت سروايمنولوزيكى در افرادى كه احتمال مواجهه شغلى وجود دارد، اهميت بالايى دارد. مطالعات مختلفى در زمينه اندازمخيرى سطوح آنتىبادى ضد آنتىثن سطحى ويروس هياتيت

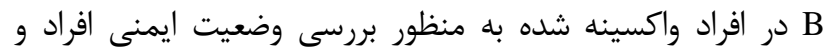

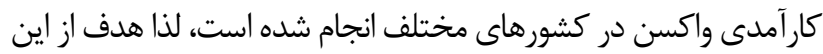
مطالعه تعيين وضعيت سروايمنولوزيك دانشجويان علوم يزشكى شيراز

$$
\text { ورودى سال ^و در برابر ويروس هياتيت B مى مباشد. }
$$




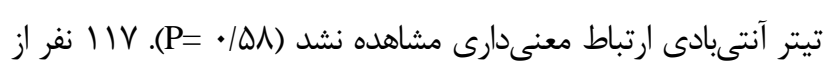

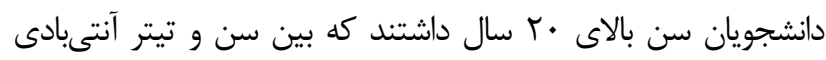

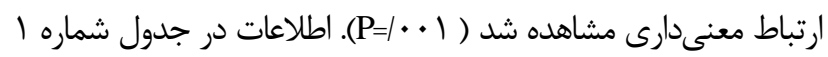
نشان داده شده است.

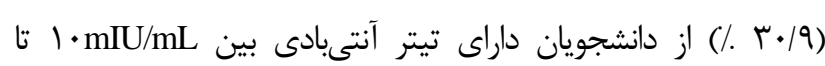
mIU/mL

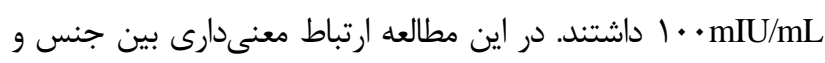

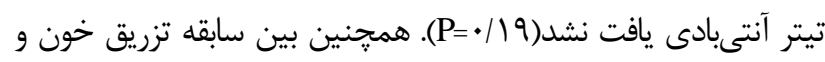

جدول ا. تغييرات تيتر آنتىبادى دانشجويان با توجه به متغير هاى مختلف

\begin{tabular}{|c|c|c|c|c|}
\hline \multirow[b]{2}{*}{$P$ value } & \multicolumn{3}{|c|}{ تغييرات تيتر آنتىبادى } & \multirow[b]{2}{*}{ متغير } \\
\hline & $\begin{array}{l}>100 \mathrm{mIU} / \mathrm{ml} \\
(\%)\end{array}$ & $\begin{array}{c}10 \mathrm{mIU} / \mathrm{ml}<\mathrm{HBs} \text { Ab Titer }<100 \mathrm{mIU} / \mathrm{ml} \\
(\%)\end{array}$ & $\begin{array}{l}<10 \mathrm{mIU} / \mathrm{ml} \\
(\%)\end{array}$ & \\
\hline \multirow{3}{*}{$P=\cdot 119$} & \multicolumn{4}{|r|}{ 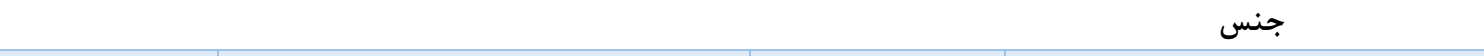 } \\
\hline & $I V(T / \Lambda I)$ & IFG(TK/VT) & $r \wedge r(\varepsilon r / \mathcal{T} \Delta)$ & مرد (FFG) \\
\hline & $r \mu(\varphi / \mu r)$ & $1 \cdot 9(Y \wedge / \vee G)$ & $\operatorname{rFG}(\mathcal{G} / q)$ & 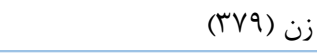 \\
\hline \multirow{3}{*}{$\mathrm{P}=\cdot 1 \cdot \cdot 1$} & \multicolumn{4}{|r|}{ سن } \\
\hline & $r q(Y / l)$ & 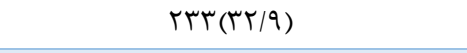 & FfG(GT) & 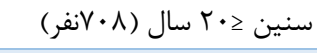 \\
\hline & $1 T(1 \cdot / T 9)$ & $r t(\mid N / N)$ & $\Lambda r(V \cdot / 9 f)$ & سنين > •r سال(VI انفر) \\
\hline \multirow{13}{*}{-} & \multicolumn{4}{|r|}{ رشته دانشجويان } \\
\hline & $\|(F / V T)$ & $V \mathcal{F}(Y / V \varepsilon)$ & $\mid F \wedge(\varepsilon r / \Delta T)$ & يزشكى (rrrrir) \\
\hline & $1 \cdot(V / Y \Delta)$ & $r \cdot(Y I / V Y)$ & $9 \wedge(\vee / / \cdot 1)$ & يرستارى(^ا| نفر) \\
\hline & $\varphi(V / \mid Y)$ & $1 N(Y I / \mathbb{R})$ & $q \cdot(V / / F T)$ & علوم آزمايشخاهى(1) نفر) \\
\hline & $r(r / V V)$ & $19(\pi \cdot / 4)$ & $r \Delta(\varsigma 9 \mid \cdot r)$ & هوشبرى(سه نفر) \\
\hline & $f(V / \wedge \Delta)$ & $I F(Y V / F Q)$ & $r(g Y / V)$ & دندانيزشكى( اله نفر) \\
\hline & $r(\varepsilon / \mid r)$ & $11(t+K A)$ & $r \Delta\left(V / / K^{\mathbb{R}}\right)$ & اتاق عمل(Fq نفر) \\
\hline & $l(T / \mu)$ & $11\left(f^{c} \cdot 19\right.$ & $r \Delta(\Delta \varepsilon / \Lambda)$ & فوريت هاى يزشكى(FF نفر) \\
\hline & $\cdot(\cdot)$ & $\|(r \mid / F)$ & $r F(\varepsilon \wedge / \varepsilon)$ & فيزيوترايى(山س نفر) \\
\hline & $r(q / r \vee)$ & $1 \cdot(r) / r \Delta)$ & । $(\Delta ৭ / \Gamma)$ & راديولوزى(r نفر) \\
\hline & $\cdot(\cdot)$ & $G(Y V / T)$ & $19(V / V)$ & مامايى(Tr نفر) \\
\hline & $I(\mathcal{F} / \Delta \Delta)$ & $V(r) / \Lambda I)$ & $\mid \mathcal{F}(\varepsilon / \mid q \Psi)$ & نفر) كار درمانى(Tr \\
\hline & $1(1 / 91)$ & rrv) & $\longleftrightarrow \wedge(\varphi) / r)$ & ساير رشته ها (Yr) \\
\hline$P=\cdot \mid \Delta \Lambda$ & $r(r / \mid V)$ & ( & $r \cdot(\varepsilon r / Q)$ & سابقه تزريق خون (†人) \\
\hline
\end{tabular}

\section{بحث}

واكسيناسيون همعانى براى اطفال را در سال \&19 1 آغاز كرد، اما اثر بخشى بلند مدت برنامه واكسيناسيون در كاهش سرطان سلولهاى

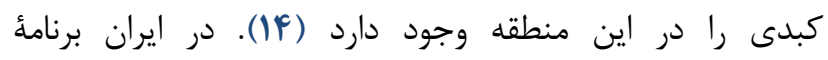

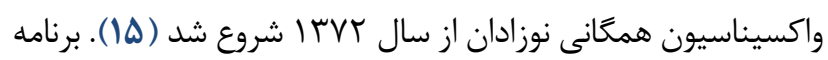

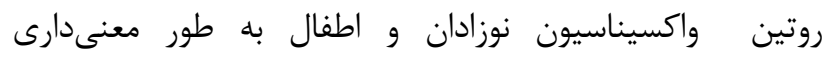

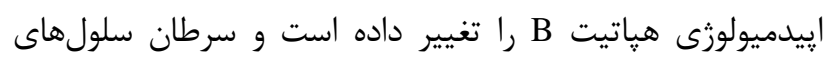

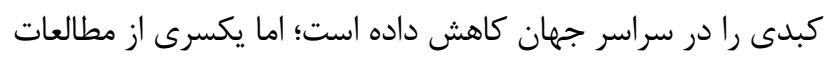

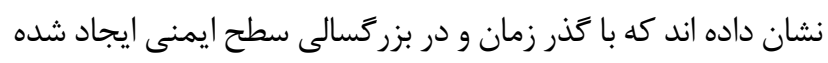

$$
\text { توسط واكسن، كاهش مىيابد (זا، ول1). }
$$

در مقاله منتشر شده توسط Amini و همكاران در سال

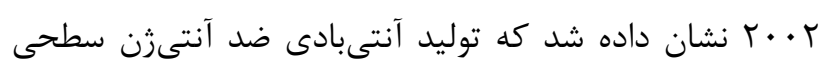

در اين مطالعه به بررسى تيتر آنتىبادى ضد آنتىثن سطحى

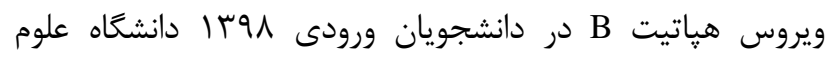

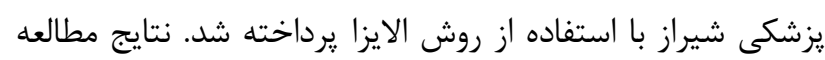

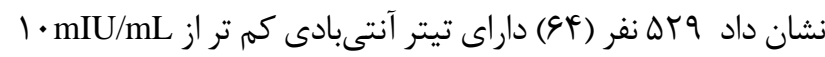
بودند كه فاقد مصونيت يا مصونيت ضعيف شناخته شدند. همجنين

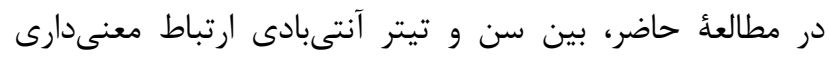

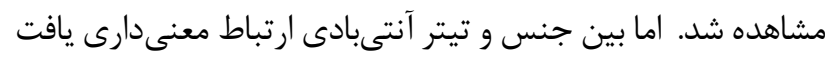
نشد. در كشورهاى ديكر نيز مطالعاتى ازين دست انجام شده است. مطالعات در كشور تايوان نشان دادند كه هرجند اين كشور يك منطقه اندميك براى عفونت مزمن هياتيت B م و سرطان سلولهاى كبدى محسوب مىشود و اولين جايى بود كه برنامه منديت 
بهتر است. البته با توجه به كاهش تيتر آنتىبادى با كذر زمان

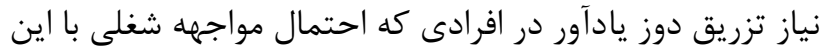
ويروس دارند، ضرورى مى باشد.

نتايج مطالعه حاضر نشان داد كه بين سن و تيتر آنتىبادى ارتباط معنىدارى وجود دارد و با افزايش سن، تيتر آنتىبادى دادي

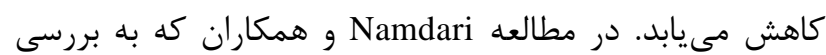
تيتر آنتىبادى در دانشجويان بخش علوم آزمايشخاهى دانشكاه

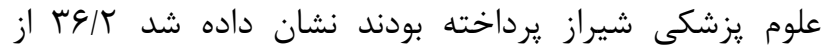

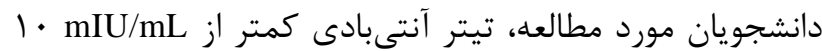

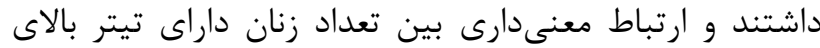

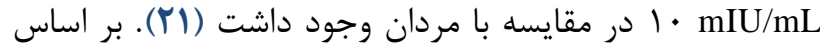
مطالعه Arefkhah و همكاران كه تيتر آنتىبادى ضد آنتىزن معابسه

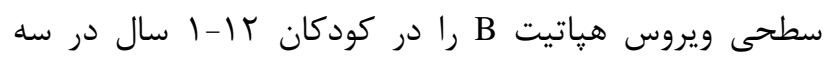
روستاى استان فارس بررسى كرده بودند، تيتر آنتىبادى در

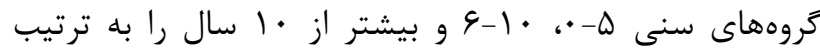
NN/V

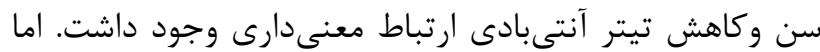
ارتباط معنى دارى بين جنس و آنتىبادى ضد آنتىزن سطحى آنى ويروس هياتيت B وجود نداشت (YT). در يك مطالعه متآناليز كه توسط Rezaee و همكاران انجام شده بود نشان داده شد با افزايش سن، تعداد ياسخ دهندًان به واكسن به طور قابل توجهى إنى

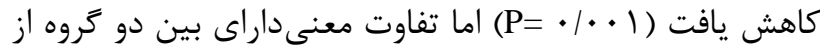
نظر جنسيت، انواع واكسن، قوميت و محل زندى آنى وجود نداشت. علاوه بر آن، در اين مطالعه متاآناليز نشان داده شد كه به بر اساس تحقيقات انجام شده در ايران و ساير كشورها بين ميزان عدم ياسخ به واكسن هياتيت B تفاوت معنى دارى وجود ندارد (r) (I). از طرف ديخر يكسرى مطالعات نشان دادهاند كه حدود ه

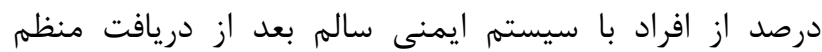

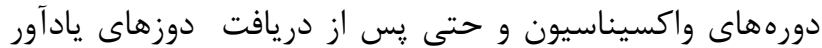

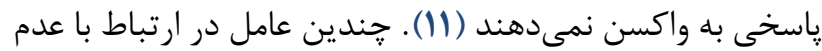

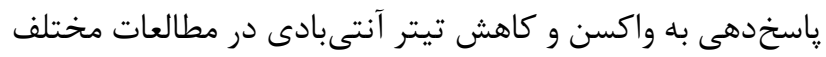

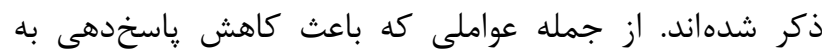

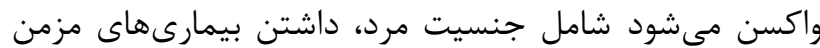
كليوى/كبدى و يا ديابت، زنتيك فرد و مصرف سيكار مى بـاشد

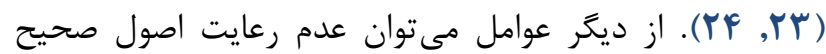
نكَهدارى واكسن مثل يخ زدن، عدم رعايت فواصل واكسيناسيون و تزريق نامناسب را نام برد (II, (YF). بعلاوه عامل ديخرى كه
ويروس هياتيت B يس از دوز دوم در كودكان 9V/9٪ و در

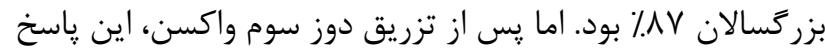

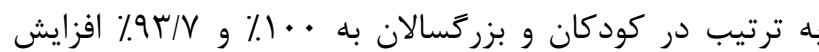
يافت. همجنين كزارش كردند كه تيتر آنتىبادى ضد آنتىزن

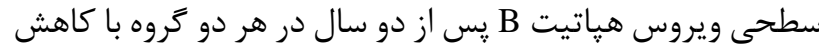

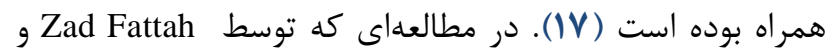
همكاران برروى دانشجويان واكسينه شده دانشكده دندان يزشكى اردبيل انجام شده بود، نشان داده شد كه

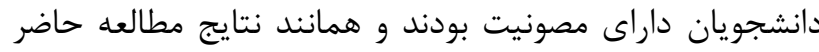
ارتباط معنى دارى بين متغير جنس و تيتر آنتىبادى ييدا نكردند.

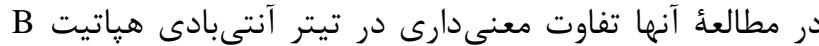
دانشجويان بيش بالينى و بالينى تزارش شد (1)(1). در مطالعأ

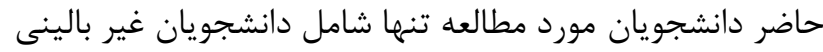

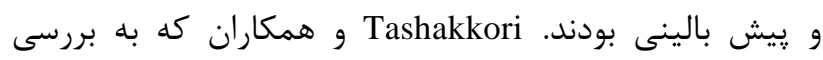
ماركرهاى سرولوزيك هياتيت B در دانشجويان دانشعاه علوم يزشكى بابل يرداخته بودند، ززارش كردند حدود ها هار درصد از

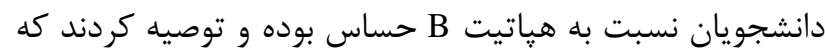
دانشجويان قبل از ورود به آموزشهاى بالينى براى اطمينان از ايمنى كافى مورد بررسى قرار بخيرند (19).

در مطالعه Lee و همكاران تيتر آنتىبادى در سنين لاماه تا

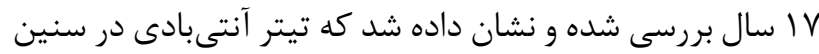

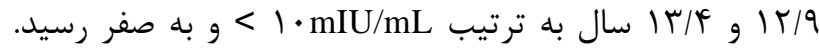
همجنين در اين مطالعه نشان داده شد كه و9 درصد كودكان بعد

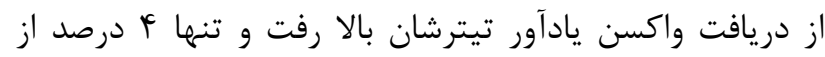
كودكان، آنتىبادى منفى باقى ماندند (•r). Norouzirad و همكاران در مطالعهاى كه به بررسى تيتر آنتىبادى در سنين اتا

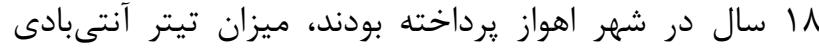
•lmIU/mL

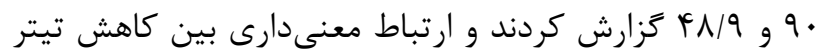
آنتىبادى با افزايش سن را نشان دادند (با). مطالعه حاضر به آنه همراه ساير مطالعات نشان مىدهند كه مقدار آنتىبادى توليد

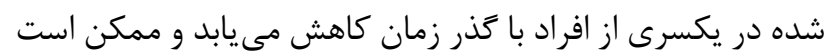

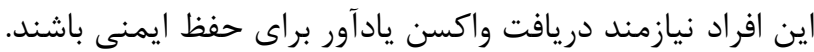
همجنين نظر مىرسد اگرجه ميزان ياسخدهى به واكسن

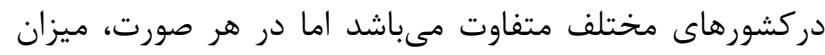

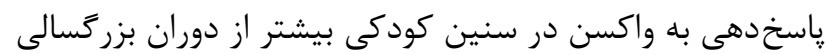

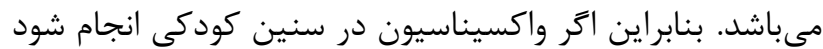




$$
\begin{aligned}
& \text { براى محافظت در برابر عفونت با ويروس هياتيت B برخوردار }
\end{aligned}
$$

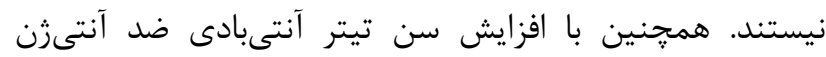

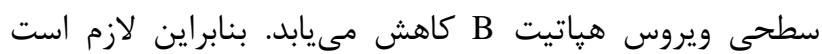

$$
\begin{aligned}
& \text { دانشجويان رشته هاى علوم يزشكى به خصوص دانشئ انشويان } \\
& \text { رشتههايى كه خطر مواجهه بالايى با اين ويروس دارند، تيتر }
\end{aligned}
$$

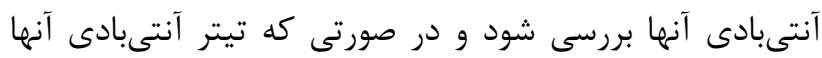

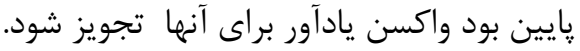

$$
\begin{aligned}
& \text { سياسگزارى }
\end{aligned}
$$

اين مقاله بركرفته از رساله دكتراى حرفه اي خانم فاطمه

هاشم زاده، دانشجوى يزشكى دانشكاه علوم يزشكى شيراز، به به ريه شماره طرح تحقيقاتى 21063-01-01-98 است. طرح اجرايى اين مطالعه با كد اخلاق IR-SUMS.MED.REC.1399.47 مورد تاييد كميته اخلاق دانشكاه علوم يزشكى شيراز قرار گرفت. از كارشناسان كروه باكترى شناسى و ويروس شناسى، دانشجويان و تمام كسانى

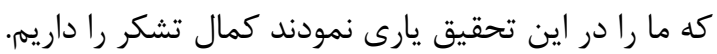

$$
\text { تعارض در منافع }
$$

در انجام مطالعأ حاضر، نويسندًان هيجَّونه تضاد منافعى

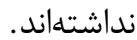

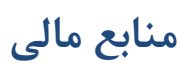

$$
\text { سازمانى انجام شده است. ئزوه، مستقل است و بدون حمايت مالى لى }
$$

\section{Referance}

1. Aspinall E, Hawkins G, Fraser A, Hutchinson S, Goldberg D. Hepatitis B prevention, diagnosis, treatment and care: a review. Occupational medicine. 2011;61(8):531-40. [DOI:10.1093/occmed/kqr136] [PMID]

2. Salisbury D, Ramsay M, Noakes K. Immunisation against infectious diseases: The Stationery Office; 2006.

3. Kao J-H. Diagnosis of hepatitis B virus infection through serological and virological markers. Expert review of gastroenterology \& hepatology. 2008;2(4):553-62. [DOI:10.1586/17474124.2.4.553] [PMID]

4. Raimondo G, Pollicino T, Squadrito G. Clinical virology of hepatitis B virus infection. Journal of hepatology. 2003;39:26-30. [DOI:10.1016/S0168-8278(03)00135-1]

5. Alter MJ. Epidemiology of hepatitis B in Europe and worldwide. Journal of hepatology. 2003;39:64-9. [DOI:10.1016/S0168-8278(03)00141-7]
در اثر بخشى واكسن و توليد آنتىبادىهاى خنثى كننده مهمه مىباشند ماهيت خود واكسن مىباشد و يكسرى استراتزىهاى مختلفى مطالعه شده يا در حال مطالعه است كه اثر بخشى دأنى واكسن افزايش קيدا كند. در واكسن نسل دوم كه در مخمر به صورت نوتركيب توليد شده تاخوردى بخشى إنى از آنتىزن سطحى

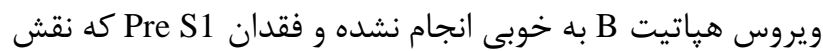
مهمى در اتصال ويروس و ايجاد آنتىبادى هاى خنثى كننده

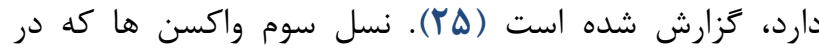

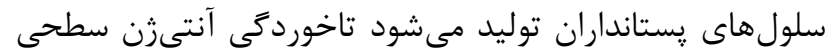

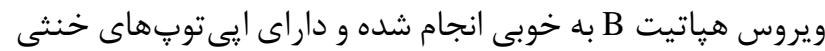

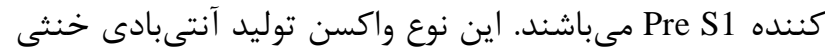
كننده را در افرادى كه به درمان ضد ويروسى ياسخ نمى دهند (Nonresponder)

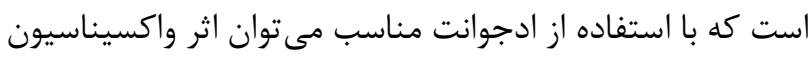
هياتيتB و رياسخ آن را در اين بيماران بهبود بخشيد (Y). Fabrizi تيموينتين به عنوان ادجوانت مى تواند منجر به افزايش ميزان

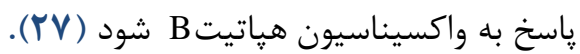

\section{نتيجه}

نتايج حاصل از اين مطالعه نشان مىدهد كه بيش از نيمى

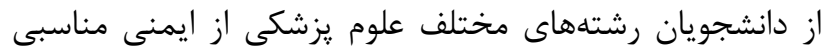

6. Fattovich G. Natural history of hepatitis B. Journal of hepatology. 2003;39:50-8. [DOI:10.1016/S0168-
[ $\underline{8278(03) 00139-9]}$

7. Hajarizadeh B, Mesgarpour B, Nasiri MJ, Alavian SM, Merat S, Poustchi H, et al. Estimating the prevalence of hepatitis B virus infection and exposure among general population in Iran. Hepatitis Monthly. 2017;17(8). [DOI:10.5812/hepatmon.11715]

8. Poustchi H, MOHAMMADNEZHAD M, Malekzadeh R. Hepatitis B virus infection in Iran. 2007.

9. Alavian SM. Hepatitis B virus infection in Iran; Changing the epidemiology. 2010. 
10. Poorolajal J, Majdzadeh R. Prevalence of chronic hepatitis $B$ infection in Iran: a review article. Journal of research in medical sciences: the official journal of Isfahan University of Medical Sciences. 2009;14(4):249.

11. Hajikazemi E. Hepatitis B vaccination. Iran Journal of Nursing. 2001;13(25):58-63.

12. Rezaee R, Aghcheli B, Poortahmasebi V, Qorbani M, Alavian SM, Jazayeri SM. Prevalence of national responsiveness to HBV vaccine after 22 years of Iranian expanded program on immunization (EPI): a systematic review and meta-analysis study. Hepatitis monthly. 2015;15(5). [DOI:10.5812/hepatmon.15(4)2015.23618]

13. Norouzirad R, Shakurnia AH, Assarehzadegan M-A, Serajian A, Khabazkhoob M. Serum levels of antihepatitis B surface antibody among vaccinated population aged 1 to 18 years in ahvaz city southwest of iran. Hepatitis monthly. $2014 ; 14(1)$ [DOI:10.5812/hepatmon.13625] [PMID] [PMCID]

14. Chang M-H, You S-L, Chen C-J, Liu C-J, Lai M-W, Wu T-C, et al. Long-term effects of hepatitis B immunization of infants in preventing liver cancer. Gastroenterology. 2016;151(3):472-80. e1. [DOI:10.1053/j.gastro.2016.05.048] [PMID]

15. Nilforushan M. EXPANDED PROGRAMME ON IMMUNIZATION AND HEPATITIS B VACCINE. Razi Journal of Medical Sciences. 1994;1:44-9.

16. Bonanni P, Pesavento G, Bechini A, Tiscione E, Mannelli $\mathrm{F}$, Benucci $\mathrm{C}$, et al. Impact of universal vaccination programmes on the epidemiology of hepatitis B: 10 years of experience in Italy. Vaccine. 2003;21(7-8):685-91. [DOI:10.1016/S0264-410X(02)00580-7]

17. Amin S, Andalibi S, Mahmoudi M. Anti-HBs response and its protective effect in children and adults receiving hepatitis B recombinant vaccine in Tehran. 2002.

18. Zad Fattah F, Blourian M, Sadegh A . The evaluation of Hepatitis B Antibody titer among vaccinated students in Ardebil College of Dentistry. Iranian Journal of Medical Microbiology; 2016;10(3): 68-72.

19. Tashakkori F, Yahyapour Y, Abdollahpour SM, Dargahi S, Bagheri M, Haji-Ahmadi M. Serological markers of hepatitis B in Students at Babol University of Medical Sciences. Iranian Journal of Medical Microbiology. 2016;9(4):79-86.

20. Lee KH, Shim KS, Lim IS, Chae SA, Yun SW, Lee NM, et al. Changes in hepatitis B virus antibody titers over time among children: a single center study from 2012 to 2015 in an urban of South Korea. BMC pediatrics. 2017;17(1):164. [DOI:10.1186/s12887-017-0924-7] [PMID] [PMCID]

21. Namdari S, Arabsolghar R, Sharifzadeh S, Farhadi A, Toopchi S, Seyyedi N, et al. Anti-HBs Antibody Levels and Anti-HBc Detection Among HBV-Vaccinated Freshmen Enrolled in the Department of Laboratory Sciences, Shiraz University of Medical Sciences, Iran.
Shiraz E-Medical Journal. 2018;19(7). [DOI:10.5812/semj.64831]

22. Arefkhah N, Vafazadeh S, Shahriarirad S, Ghorbani F, Zoghi S, Emami M, et al. Serum levels of anti-hepatitis B surface antibodies among vaccinated children aged 1 to 12 years in a rural community in Fars Province, southern Iran. Journal of Immunoassay and Immunochemistry. 2019:18. [DOI:10.1080/15321819.2019.1675696] [PMID]

23. Walayat S, Ahmed Z, Martin D, Puli S, Cashman M, Dhillon S. Recent advances in vaccination of nonresponders to standard dose hepatitis B virus vaccine. World journal of hepatology. 2015;7(24):2503. [DOI:10.4254/wjh.v7.i24.2503] [PMID] [PMCID]

24. Nejad HN, Ghorbani G, Razaghi R, Akbari H. Comparison of Two Recombinant Hepatitis B Vaccines. Hepatitis Monthly. 2009;9(3).

25. Roberts S. DNA tumour viruses: virology, pathogenesis and vaccines: Caister Academic Press; 2018.

26. Cooper C, Mackie D. Hepatitis B surface antigen-1018 ISS adjuvant-containing vaccine: a review of HEPLISAVTM safety and efficacy. Expert review of vaccines. 2011;10(4):417-27. [DOI:10.1586/erv.10.162] [PMID]

27. Fabrizi F, Dixit V, Martin P. Meta-analysis: the adjuvant role of thymopentin on immunological response to hepatitis B virus vaccine in end-stage renal disease. Alimentary pharmacology \& therapeutics. 2006;23(11):1559-66. [DOI:10.1111/j.13652036.2006.02923.x] [PMID] 